\title{
Iranian Student's Emotion in Government University in Malaysia
}

\author{
Mehrnoosh Akhtari-Zavare (Corresponding author) \\ Department of Community Health, Universiti Putra Malaysia \\ Po box 43300, Serdang, Selangor, Malaysia \\ Tel: 60-1-7355-6753/60-3-4252-5941 E-mail: akhtari_mehrnoosh@yahoo.com \\ Abbas ghanbari-baghestan \\ Department of Communication, Limkokwing University of Creative Technology \\ Po box 63000, Cyberjaya, Selangor Darul Ehsan, Malaysia \\ Tel: 60-1-2274-8576 E-mail: dr.abbas@limkokwing.edu.my
}

\begin{abstract}
Learning situations in modern society are getting increasingly complex and variable, and learners have to take more responsibility for their own learning. The main purpose of this study was to understand Iranian student's feelings, who studying in selected Government University in Malaysia. The study was carried out through three research questions: 1) How do the Iranian student's feel about life in Malaysia? 2) How these feelings do affects on Iranian student's educational progress? 3) What are the factors that contributed to these feeling? Due to the nature of study, a qualitative research method and techniques was used to enable the researcher to understand emotion of Iranian student whose study at one of Government University in Malaysia. Data was gathered from interview with 3 Iranian students via "convenience sampling". "Constant Comparative" method was used for data analysis. Eight major themes (worry, sad, happy and comfortable, socio-culture factors, economic factors, and good relationship and environment facilities) emerged from this study in relation to Iranian student's emotion in selected Government University in Malaysia. This study concludes that based on the findings, graduated student organization can designed intervention program base on International students' views in their social, cultural and economical content.
\end{abstract}

Keyword: Student's emotional, Learning strategy, Malaysia

\section{Introduction}

Learning situations in modern society are getting increasingly complex and variable, and learners have to take more responsibility for their own learning. In every day learning situations there are different kinds of competitive motives, disturbing emotions or environmental and social factors that influence the learning process (Pintrich, 2000).

In learning situations, individuals make personal appraisals of the situations, meaning based on their former knowledge and experiences. These appraisals along with situational factors and the individual's interpretations of them arouse emotions (Fredrickson, 2001).

In addition, research on emotions has shown that students experience a rich variety of emotions in academic settings. Also, the results of previous research show that academic emotions are significantly related to student monitoring, learning strategies, cognitive resources, self regulation and academic achievement. Moreover, not only do the emotions themselves vary, but also their sources. The student's emotion in adopting himself/herself with the new condition is very important, since this adaptation is very affective on the level of satisfaction and consequently on student's educational progress.

According to Ciccareli and Meyer, (2006) there are important links between emotions and cognition. Also the label a person applies to a subjective feeling is influenced by that person's language and culture. Therefore, what is the meaning of emotions for Iranian students, as the majority of international students, and how do these emotions affect their educational progress in selected Government University in Malaysia. Thus, this study aims to understand the Iranian postgraduate third semester student's emotions in selected Government University in Malaysia. 
As the Iranian students is going to be the majority of international students in selected Government University in Malaysia, it seem that, paying due attention to their point of views and understanding their emotions are necessary, since these emotions influence on their educational progress. It seems the selected Government University in Malaysia lectures in general, and committee supervisory members in particular, do not pay enough attention to understand the Iranian students' emotions during their educational experience in selected Government University in Malaysia. Data is needed to help them plan appropriate programs for international students. In addition, there is not any research about concepts related to education emotions in cultural, social, and economic context to Iranian graduate students in overseas.

The purpose of this study is to understand Iranian student's feelings, who studying in selected Government University in Malaysia. The researcher questions to be answered through this study are:

1. How do the Iranian student's feel about life in Malaysia?

2. How these feelings do affects on Iranian student's educational progress?

3. What are the factors that contributed to these feeling?

\section{Methodological Issues}

Due to the nature of study, a qualitative research method and techniques was used to enable the researcher to understand emotion of Iranian student whose study at one of Government University in Malaysia. In this study researcher selected 3 Iranian students via "convenience sampling" because saves time, money, and effort, but at the expense of information and credibility. The following criteria were used in the sampling procedure; Being in the third semester of education and Interested to participate in the study. In the present study, in depth, semi structured interview (Berger, 2000; Mason, 1996) was the preferred method because they yield an understanding of a person's experiences and perspectives, help verify and validate information gleaned from other references, allow actors to relate accounts in their own words, and gather information that cannot be observed effectively (Lindlof \& Taylor 2002).

\subsection{Procedure of Interview}

In this study before conducting interview, the researcher developed an interview guide for interview. Also, the questions for the interview guide were based on literature review. The interview questions consisted of two areas that were relevant to the phenomenon being studied. These areas were introduction and some questions related to emotion of Iranian student. The researcher herself conducted the interviews sessions. The sessions were done in one month that was October 2009. All of respondents were interviewed face-to-face. All subjects were also interviewed independently of one another in order to avoid "group speak".

Before interviewing the respondents, the researcher gave some background information of herself and also the purpose of study. All interviews were recorded on audio tape or digital recorder since all the respondents gave their consent.

Interviews ranged from 45 to 90 minutes in length, averaging about 65 minutes each. Following the completion of each interview, materials from the transcriptions were grouped by similarities as patterns emerged (tentative analysis). After each interview, tentative analysis was done and then was used for improving the following interview. In this study, interviews were done with 4 respondents because data saturation had been reached by then. This was discovered when all the tentative findings from respondent No.1 to respondent No. 3 seems to be same.

\subsection{Ethical consideration}

In qualitative research, when human participants are involved, some ethical and legal consideration should be taken into account. Since human beings have certain rights, the researcher must ensure that the rights of participants in a study are not violated. Although there is no universal definition of ethical issues, a series of guidelines, broad generalizations, and suggestions have been endorsed or at least accepted by most in the research profession.

For this study, before conducting data collection, a letter (inform consent) was sent to the selected participants describing the purpose of the study. All participants were informed that data recorded with special code names, so that is not link between these codes and the subject's identity. Names of the subjects were known only to the investigators, who will hold this information in the strictest confidence, coded, and securely stored in a stored in a locked file. All of tapes and documents related to research after completing research were destroyed.

Also, respondents were informed that an interview may take averaging about 70 minutes, or that a second interview is required. Besides these, whenever the interviewees requested a copy of the interview questions, it was 
sent to them two or three days before the actual interview date. Therefore, all interviews were conducted only when potential subjects volunteered to participate in this study.

\subsection{Data Analysis}

The process of data analysis involves the organization and categorization of all the collected data from the available sources of evidence in such manner as to make sense of what has been learned. Merriam (1998) mentioned that in qualitative research, data collection and data analysis should be a simultaneous process as both occur in and out of the field. Based on her idea, therefore, data analysis is about organizing and interpreting data to make meaning. Since the researcher is the instrument, the analysis will depend on upon an investigator's creative abilities as much as upon his or her technical expertise.

In this study, the data mainly come from the transcripts of the interviews with the respondents. To triangulate this data, the interview transcript from the respondents was analyzed. The process of data analysis and data gathering were done simultaneously. The process of data analysis for interviews began after the first interview and tentative analysis for each transcribed interview was also done.

A technique called constant comparative method by Strauss and Corbin (1998) was used for data analysis. The Strauss and Corbin method (1998) involved three different types of analysis (open coding, axial coding, and selective coding) and resulted in increasing levels of interpretation and abstraction of the analysis.

In this study, when open-coding data was examined line by line to identify and name the concepts expressed by the respondents in each transcript, concepts and categories were labeled with words used by the students to ensure the respondent's meanings were captured as closely as possible.

In this study, during axial coding, memos and diagrams were used to document the process and to capture relationships between categories and subcategories. A coding paradigm was also used to specify a category in terms of the conditions that gave rise to its context, intervening condition, action, interaction strategies, and resultant consequences. For this study, because of limited number of respondents researcher could not find a core category.

\section{Findings \& discussion}

In this study, the students shared their emotions of living and staying in Malaysia. Analysis of the data occurred by questions. In the first phase of the data analysis, student's different kinds of descriptions of their emotional expressions were identified. After several repeated coding sessions four coding categories were formulated based on the dialectics of data. The categories were worry, happy, sad and comfortable. The coding was conducted independently by researcher.

\subsection{Feeling about living in Malaysia}

When students were asked to reflect on their feeling about living in Malaysia, the following four categories were emerged from the participant's descriptions their feeling about their life in Malaysia included: (i) worry, (ii) happy, (iii) sad (iv) Comfortable.

\subsubsection{Worry}

Data from this study suggest that lack experience of living in abroad, economical issue, health issues and being safe important factors to make sense of worry in Iranian students.

For instance respondents number 2 said with serious tone: "I was very worry at the first because I have come with my family and we did not have any experience about living in abroad, I always thinking about bad occurring events for my family"

Also, this respondent believed that: "Here, having no monthly income leads to a feeling of insecurity".

\subsubsection{Happy}

The second category emerged from this study is "happy". For all respondents "happy" was along with new experience of life. This category further divided into two subcategories; including:

\subsubsection{Achieve new experiences}

All participants mentioned that they have had"unique experience, positive events', 'different living style', and 'adaptation with living in abroad.

For instance respondents number 2 said: "In order I am very happy that I experiencing different life style in my life"

Regarding to the above feeling respondent number 3 also said: 
"Leaving in Malaysia was a good experience in my life, because it was my first time to live alone far from my family. I learned how to manage my daily life \& how to answer to my inquires alone"

\subsubsection{Good environment}

The next subcategory for the "happy" was good environment. All respondents described that Malaysia has a good environment for living. They reasons for this opinion is "green country", "have some attractiveness", "peaceful social environmental", "having many international and local congress and conferences".

In this regard respondent number 3 was believed: "Malaysia's green life makes me feel fresher".

Along with the above argue; respondent number 4 also was agree; said: "This country has some attractiveness for living that need a few years time for understanding them... all creates a favorite place for living".

Also, respondent number 3 talked more about national and international events in Malaysia: "Take place of many international and local congress and conference should be considered as a one of the best advantages for educated people in Malaysia".

\subsubsection{Relationship}

The last subcategory for "Happy" is the concept of relationship. Two out of three respondents mentioned that good relationship with lectures, staffs and people has affect on their sense of happy.

According to respondent number 3:"In spite of some problems, I feel that I am happy in Malaysia due to friendly relationship of Malaysian people with the foreigners".

Also, respondent number 2 said: "Malaysian people are very calm and friendly. You hardly see a quarrel, therefore when you go out and come back then you do not upset".

\subsubsection{Sad}

The third category for the finding of this study is "sad". All respondents were believed that they become sad some times because of "food, unfamiliar condition, and homesickness, Malay-English accent".

For instance respondent number 1 said:

"When I live in Iran somehow my life is better than here. Now, I live far from my family, so I miss them. Also, in my country I eat healthy food and did some exercise. I familiar with my country and have a lot of closed friends."

Also, another respondent said:

"In my point of view, we all live a "student life" here in Malaysia. means feeling homesick, dining out instead of cooking at home, having no food schedule, staying up late at night, challenging to get used to the new food tastes, having some difficulties with understanding Malay-English accent".

Homesickness is among the most frequently reported concerns of international college students in the United States (Yi, Giseala Lin, \& Kishimoto, 2003). Missing family, missing friends, feeling lonely, adjustment problems, and home ruminations cause homesickness among international students (Willis et al., 2003). Also, they found that international students experienced less social support than domestic students, most likely because their family and friends were at a greater distance.

\subsubsection{Comfortable}

The last for question number one is "comfortable". Participants describe their feeling of life in Malaysia comfortable. They feel here "more relax".

For instance one of the respondents when compare life experience in Iran and Malaysia said:

"Having the life expenses in both Malaysia and Iran compared, I surely am experiencing a much smoother lifestyle with least sense of daily stressfulness that I used to encounter at my office in Iran. Here - in Malaysia, stress has lost its very meaning"

Similarly respondent number 3 was believed that in Malaysia she is more relaxed because away from job: "My personal life in Iran was totally different from here. Here we feel more relaxed because we are away from work challenges and only focusing on the academic purposes".

\subsection{Affect of feeling on students educational progress}

Two categories emerged from the participants explain how their feelings affect on their educational progress include: positive affects, and negative affects. 


\subsubsection{Positive affects}

When respondents explain about the positive effect of feeling on educational progress, two subcategories were emerged as (a) don't have any problem (b) relationship between students and Academic staff.

\subsubsection{Don't have problem}

True analyzing the data come from this study, several factors that participants mentioned that have positive effects on their educational progress are as bellow: "free of stress", "stability and feeling of secure" "environment is favor", "not financial problem", "quality of university".

Regarding the facilities of university respondent number 2 said:

"The facilities and encouragements supplied by the university and the supervisor(s) and the facilities provided by them, such as the encouragement supplied to the student to introduce to the academic life by publishing scientific journal paper or participating in either local or international conferences. The selected University is going in progress to improve this part of development magnificently."

Also this respondent believed the most important factor affecting the educational progress is stability. He said:

"The most important factor affecting the educational progress for a student is the stability and feeling of security not only for belongings, but for the educational scope. Beside that, the stability can be described as the chances for the student to improve himself with any effort the student give, while the security of the ownership of the work to be assigned to the student himself".

Same as the above argument respondent number 2 said:

"When we do not have any problem and there is nothing to district our mind. I mean our mind is free of some stress, my environment is favor. Also, have not financial problem we can focus on our studies and this brings about progress in education"

\subsubsection{Relationship between students and academic staff}

The nest subcategory of the positive effect of the feeling on educational progress is relationship between students and academic staff. All of participants believed that friendly behavior between students and academic staff has important affect on their educational progress, because this relationship increases their self confidence.

In this regard respondent number 2 talking about his relationship with his supervisor said:

"Here friendly behavior between students and academic staff well in one hand and availability of source of study and good facility in other hand, caused you are in good position of sense of education. This situation helps students enhance their quality of study and being more successful in their field study".

On the other hand this respondent believed that:

"The chairperson of my supervisory committee can be considered as a role model in being a friendly and encouraging academician who would like to share knowledge as much as possible with students".

This finding seems to support Bassnett (2003) findings in his study that a good relationship between supervisor and student is one of the most important factors for student education progress. Wisker (2003) commonly agreed that 'a good supervisor-student relationship can only thrive if both parties share mutual expectations and have established ground rules about the regularity, type and focus of supervisions'

\subsubsection{Negative effects}

The negative effect was the second category for the effect of feeling on educational progress. Participants described that having problem with methods of teaching, discriminate against international student, and communication which effects on their educational progress.

For instance respondent number 3 said: "Here in Malaysia, lecturers somehow discriminate against international students. For example in some of the international classes some lecturers distributed hand outs in Malay!"

While she was depressing about her situation, she continues:

"Other thing, lecture should work on their English language proficiency in order to communicate better with international students and only some of them are well-educated, not all! For example, one of the proficient lecturers of my own, was not able to convey his meaning in English, although he was unique in his field, jut in Malay"

Another respondent of this study agree that: "We have a workshop class with technician whom can't speak English at all". 
One more things that were highlighted by respondent of this study was wrong method of teaching in Malaysia based on their opinion for example:

"Here you can't learn more in the class, the lecture just give you some outline and you have to go through it to learn more. The method of teaching so different from my country and I disturb a lot".

This finding can support by Jacob, (2001) that International students participating in a cultural exchange program with graduate counseling practicum students indicated a greater need to adjust to American culture, understand non-verbal behavior, develop friendships with diverse peers, communicate effectively with professors and are involved in the university community.

\subsection{Factors affect on students feelings}

The third question of this mini-research was about factors affect on student's feelings. During this study four categories emerged from the participant's descriptions of factors affect on their feelings; (i) socio-cultural factors (ii) economical factors (iii) good public relationship (iv), and environmental facilities

\subsubsection{Socio-cultural factors}

There are many complex challenges facing students travelling to other countries to undertake university or other educational courses, particularly if their home country culture is strikingly different from the host country culture (Garry et al. 2006). In this study, one of the participants believed that social and cultural factors have important affect on Iranian student's feelings. These international students provide evidence of feelings of discomfort, dislocation and distress but their responses are, for the most part, not at an extreme level.

For instance respondent number 1 said: "I miss the familiar way of life in my own country; people treat me differently because of my cultural background".

Also, she said: "Because the culture and behaviour of people whom I faced with them in my daily life is too different from mine and sometimes it's rude in my culture".

This finding also support Ward (2001) study that found the more differences between international students' home and host cultures, the more homesickness and acculturative stress experienced. Cultural stress is an obvious challenge to the well-being of international students, particularly where the home and host countries are culturally distant.

\subsubsection{Economical factors}

The second category of last question is economic factors. All of the participants described that economical factors such as "cost of living", "tuition fee" and etc have important role in making their feelings.

Respondent number one said:" It is very difficult to pay rent of my house monthly"

Accordingly respondent number 2 said: "Economic factor is the first factor, which can by itself improve the socio-culture and environment".

In the same vein, in the study conducted by Andrade (2006), he reported economic factors are the important factor for students from abroad.

\subsubsection{Good public relationship}

All of participants explained that relationship between students and the public is one important factor that affects their feelings. Also they believed that Malaysian peoples living very simple and they are much contented peoples. This type of living brings them to be very quit and satisfied in their living.

For example respondent number 3 acknowledged that:

"Malaysian people are so easy going people, encounter with problems easier than we do, obey the laws and respect to them and have good temper. This is the main issue that you habit to be patient even with your important jobs like your thesis".

\subsubsection{Environmental facilities}

The final category for question number three is environmental facilities. Participants described that environmental facilities such as availability of high tech material, access quipped library, having recreation activities have role in their feeling.

For instance respondent number 3 said: "The newest books and resources are available here and as a student I have no problem to find anything". 
The finding of this study is similar to Gatfield (1999) among 359 undergraduate international business students studying at a South East Queensland University asking them what they considered important factors for good university. The study revealed that the following four factors were considered the most important for quality of university: Academic instruction (e.g. good teaching, course content), Recognition (e.g. by potential employer, by government, etc.), Campus life (e.g. campus housing, sports facilities, public transport), Guidance (e.g. handbooks, international office).

\section{Conclusion}

In conclusion, this study provides a better understanding on the emotion of Iranian student in Government University in Malaysia. From this study, certain socio-culture factors, economic factors, good relationship and environment facilities influence the emotion of Iranian students. On the other hand, theses emotion of students included worry, sad, happy and comfortable which has positive and negative effect on education progress in University and living in Malaysia. Consequently, based on the findings obtained from this study, graduated student organization can designed intervention program base on International students' views in their social, cultural and economical content? Also the strategies obtain based on the findings of this study improve relationship between University's staff and International student's. Graduated Student Organization should be increase attention to emotional domain, helps to adjustment with living in overseas and increase educational progress for international students.

\subsection{Implication}

The findings of this study have some implication for different parts of Selected University. For example, the graduated student organization can design intervention program base on International students' views in their social, cultural and economical content. Also, based on this result Graduated Student Organization can improve relationship between University's staff and International student's increase attention to emotional domain, helps to adjustment with living in overseas and increase educational progress. Finally, Graduated Student Organization can provide programs for better support of overseas students and improve their quality of life.

\subsection{Recommendation for Future Studies}

This study is limited to three participants studied at one Government University in Malaysia. A more in-depth study that involves more Iranian students those studied in different Universities in Malaysia with different program and field of studies. The finding from deeper and wider spectrum of study will provide more comprehensive and through collection of the understanding of emotion's Iranian students in Malaysia.

\section{Reference}

Andrade, M.A. (2006). International students in English-speaking universities: Adjustment factors. Journal of Research in International Education, 5, 131- 154.

Bassnett, S. (2003). Be Rigorous at the Start and the Marriage Will Survive. The Times Higher Education Supplement, 10 October: 23.

Berger, A. (2000). Media and Communication Research Methods: An Introduction to Qualitative and Quantitative Approaches ( $5^{\text {th }}$ ed.). London: Sage Publication.

Fredrickson, B.L. (2001). The role of positive emotions in positive psychology: The broaden-and-build theory of positive emotions. American Psychologist, 56, 218-226.

Garry, T., \& Doreen, R. (2006). Cultural stress among international students at an Australian university. Australian International Education Conference 2006 - www.idp.com/aiec.

Gatfield, T.J., Barker, M. \& Graham, P. (1999). Measuring Student Quality Variables and the Implications for Management Practices in Higher Education Institutions: An Australian and International Student Perspective. Journal of Higher Education Policy and Management, 4(2), 73-9.

Jacob, E. (2001). Using counselor training and collaborative programming strategies in working with international students. Journal of Multicultural Counseling and Development, 29, 73-88.

Lindlof, T., \& Taylor, B. (2002). Qualitative Communication Research Methods ( $2^{\text {nd }}$ ed.). Thousand Oaks, Ca: Sage Publications.

Mason, J. (1996). Qualitative Research. Thousand Oaks: Sage Publication.

Merriam, S.B. (1998). Qualitative research and case study application in education. Jossey Bass publishers, San Francisco. 
Pintrich, P. R. (2000). The Role of Goal Orientation in Self-Regulated learning. In M. Boekaerts, P. R. Pintrich, \& M. Zeidner (Eds.), Handbook of self-regulation. pp. 451-502. San Diego: Academic Press.

Strauss, A. L., \& Corbin, J. (1998). Basics of Qualitative Research. Thousand Oaks: Sage.

Ward, C., Bochner, S., \& Furnham, A. (2001). The psychology of culture shock. London: Routledge.

Willis, H., Stroebe, M., \& Hewstone, M. (2003). Homesick blues. The Psychologist, 16, 526-528.

Wisker, G. (2003). Tough Love Works for Fledglings. The Times Higher Education Supplement 13 June: 24.

Yi, J. K., Giseala Lin, J. C., \& Kishimoto, Y. (2003). Utilization of counseling services by international students. Journal of Instructional Psychology, 30, 333-342. 